\title{
Diálogo entre conhecimentos acadêmicos e saberes tradicionais em um curso de
}

\section{licenciatura a distância}

\author{
Dialogue between academic knowledge and traditional knowledge in a distance license course \\ Diálogo entre conocimientos académicos y conocimientos tradicionales en un curso de licencia a \\ distancia
}

Recebido: 25/03/2021 | Revisado: 31/03/2021 | Aceito: 31/03/2021 | Publicado: 04/04/2021

Juliane Paprosqui
ORCID: https://orcid.org/0000-0002-3034-2453
Universidade Federal de Santa Maria, Brasil
E-mail: juliane_paprosqui @ hotmail.com
Liziany Müller Medeiros
ORCID: https://orcid.org/0000-0001-7325-6611
Universidade Federal de Santa Maria, Brasil
E-mail: lizianym@hotmail.com
Ivanio Folmer
ORCID: https://orcid.org/0000-0002-7433-6434
Universidade Federal de Santa Maria, Brasil
E-mail: ivaniofolmer@yahoo.com.br
Gabriella Eldereti Machado
ORCID: https://orcid.org/0000-0001-5908-4753
Universidade Federal de Santa Maria, Brasil
E-mail: gabriellaeldereti @gmail.com

\section{Resumo}

O artigo que se apresenta é o resultado de uma pesquisa que envolveu 90 (noventa) discentes de uma disciplina intitulada "Seminário Integrador V", do curso de Licenciatura em Educação do Campo ofertado na modalidade a distância pela Universidade Federal de Santa Maria em parceria com a Universidade Aberta do Brasil. Estes alunos pesquisaram diversas práticas de agricultura sustentável e saberes produzidos no campo, registrando-os em relatórios apresentados ao final da disciplina. Retornando o total de 33 (trinta e três) relatórios destas práticas pesquisadas analisados neste artigo. Os locais pesquisados foram na abrangência do espaço rural dos polos de apoio presencial do curso são eles: Polo de Agudo, São Sepé; Seberi, Itaqui e Cerro Largo, todos no estado do Rio Grande do Sul. A metodologia seguida foi análise qualitativa dos relatórios apresentados, precedida da pesquisa bibliográfica que deu arcabouço teórico sobre as temáticas. Os resultados apontam para a necessidade de elucidar no futuro educador do campo a sensibilidade e a importância da valorização dos saberes tradicionais. Entendendo também que a educação do campo parte do respeito do modo de vida das populações campesinas, tendo a compreensão ampliada de seu papel de futuro educador do campo capaz de promover a articulação entre a escola e a comunidade.

Palavras-chave: Dialogues; Teacher training; Traditional knowledge.

\begin{abstract}
The article that is presented is the result of a research that involved 90 (ninety) students of a discipline entitled "Seminar Integrador V", from the Degree Course in Rural Education offered in distance mode by the Federal University of Santa Maria in partnership with the Open University of Brazil. These students researched several sustainable agriculture practices and knowledge produced in the field, recording them in reports presented at the end of the discipline. Returning the total of 33 (thirty-three) reports of these researched practices analyzed in this article. The surveyed places were in the scope of the rural space of the classroom support centers of the course are: Polo de Agudo, São Sepé; Seberi, Itaqui and Cerro Largo, all in the state of Rio Grande do Sul. The methodology followed was a qualitative analysis of the reports presented, preceded by the bibliographical research that gave theoretical framework on the themes. The results point to the need to elucidate in the future educator in the field the sensitivity and the importance of valuing traditional knowledge. Also understanding that rural education is based on respect for the way of life of rural populations, with an expanded understanding of their role as future rural educators capable of promoting the articulation between the school and the community.
\end{abstract}

Keywords: Dialogues; Teacher training; Traditional knowledge. 


\begin{abstract}
Resumen
El artículo que se presenta es el resultado de una investigación que involucró a 90 (noventa) estudiantes de una disciplina titulada "Seminario Integrador V", de la Licenciatura en Educación Rural que ofrece en modalidad a distancia la Universidad Federal de Santa María en alianza con el Universidad Abierta de Brasil. Estos estudiantes investigaron varias prácticas de agricultura sostenible y conocimientos producidos en el campo, registrándolos en informes presentados al final de la disciplina. Devolviendo el total de 33 (treinta y tres) informes de estas prácticas investigadas analizadas en este artículo. Los lugares encuestados que se encuentran en el ámbito del espacio rural de los centros de apoyo al aula del curso son: Polo de Agudo, São Sepé; Seberi, Itaqui y Cerro Largo, todos en el estado de Rio Grande do Sul. La metodología seguida fue un análisis cualitativo de los informes presentados, precedido de la investigación bibliográfica que dio marco teórico a los temas. Los resultados apuntan a la necesidad de dilucidar en el futuro educador en el campo la sensibilidad y la importancia de valorar los conocimientos tradicionales. Entendiendo también que la educación rural se basa en el respeto a la forma de vida de las poblaciones rurales, con una comprensión ampliada de su rol como futuros educadores rurales capaces de promover la articulación entre la escuela y la comunidad.
\end{abstract}

Palabras clave: Diálogos; Formación de profesores; Conocimientos tradicionales.

\title{
1. Introdução
}

O diálogo entre conhecimentos acadêmicos e saberes tradicionais deve permear já na formação inicial dos professores que atuam nas escolas do campo, uma vez que, parafraseando Molina \& Sá (2012) “o conhecimento científico também é um produto histórico e social". Nesse sentido, o curso de Licenciatura em Educação do Campo da Universidade Federal de Santa Maria (UFSM), ofertado na modalidade a distância (EAD) em parceria com a Universidade Aberta do Brasil (UAB) busca através da agroecologia, eixo norteador do currículo, fazer esse debate dos conhecimentos apreendidos na academia e àqueles que foram apreendidos em ambientes diversos, os quais passados de geração em geração se tornam saberes tradicionais, conforme o Projeto Pedagógico do Curso: “A Agroecologia com a educação formal/escolar proporcionará uma aproximação dos saberes das agriculturas no manejo sustentável dos agroecossistemas com a docência na educação básica" (MEC, 2017).

Esses momentos normalmente são trabalhados nas disciplinas nomeadas de Seminários Integradores, as quais perpassam o currículo desde o segundo semestre do curso até o oitavo e último semestre.

Os desafios em torno da legitimação dos saberes das populações campesinas são de longa data conhecida, havendo grandes avanços nas últimas décadas, através da comprovação da eficiência e eficácia, por exemplo, de sistemas agroecológicos. Sendo assim, a educação do campo pensada para o campo e suas populações pode dar subsídios importantes para a emancipação dos agricultores e comunidades tradicionais que ousam pensar alternativas contra um sistema hegemônico e uma agricultura voltada a monocultivos em larga escala.

Tendo como base os princípios que fundamentam a Educação do Campo e sua relação intrínseca com os conhecimentos tradicionais, os educandos do $6^{\circ}$ (sexto) semestre do curso de Licenciatura em Educação do Campo realizaram uma pequena pesquisa, na disciplina de Seminário Integrador V cujo objetivo era: "refletir interdisciplinarmente os conteúdos abordados nas disciplinas do $6^{\circ}$ semestre a partir da temática a interculturalidade e os diálogos entre saberes sociais e tradicionais: um olhar sobre a realidade local.” (MEC, 2017). Então, o solicitado para os acadêmicos foi identificar em uma comunidade ou organização familiar saberes tradicionais que foram passados de geração em geração, procurando fazer a interlocução destes saberes com o conhecimento produzido na academia, ao final da disciplina produziram um relatório confrontando os dados levantados e a relevância para sua formação enquanto futuros educadores do campo.

Tendo em vista o exposto o presente artigo busca relatar, tendo como base a pesquisa realizada pelos licenciandos, como estes percebem/entendem a importância dos saberes tradicionais elucidados para sua formação acadêmica.

A proposta da pesquisa que foi solicitada aos licenciandos se justifica pela necessidade de elucidar no futuro educador do campo a sensibilidade e a importância na valorização dos saberes tradicionais entendendo que a educação do campo parte do respeito, da valorização da luta, do entendimento da cultura e do modo de vida das populações campesinas, construindo 
conhecimento com esses sujeitos para que se tornem cada vez mais emancipados da relação de subserviência que ainda é presenciado no campo.

\subsection{Educação do Campo e Sustentabilidade}

Primeiramente a que se considerar o que a Educação do Campo não é, ao contrário do que muitos pensam, apenas uma modalidade educacional como também é definida na Lei de Diretrizes e Bases da Educação, 9.394 de 20 de dezembro de 1996. Mas muito, além disso, essa modalidade afirma a luta por uma concepção de educação, do campo e para o campo protagonizada por seus sujeitos, buscando uma educação emancipatória e não mera reprodução dos sistemas de ensino urbano, ela nasce como "crítica à realidade da educação brasileira, particularmente à situação educacional do povo brasileiro que trabalha e vive no campo" (Caldart, 2009, p. 39).

Sendo assim, se assenta como resultado da luta dos trabalhadores do campo e suas organizações por uma política educacional que atendesse aos interesses dos campesinos posicionando-se contra o modelo hegemônico ditado pelo estado. Segundo Molina \& Freitas (2011, p. 24):ç

A intencionalidade de um projeto de formação de sujeitos que percebam criticamente as escolhas e premissas socialmente aceitas, e que sejam capazes de formular alternativas de um projeto político, atribuiu a escola do campo uma importante contribuição no processo mais amplo de transformação social. Ela se coloca o desafio de conceber e desenvolver uma formação contra-hegemônica, ou 10 seja, de formular e executar um projeto de educação integrado a um projeto político de transformação social liderado pela classe trabalhadora, o que exige a formação integral dos trabalhadores do campo, no sentido de promover simultaneamente a transformação do mundo e a autotransformação humana.

Para que essa educação fosse formalizada, se fazia necessário pensar em políticas públicas que dessem sustentação às reivindicações. Então, um dos primeiros movimentos nacionais foi a Articulação Nacional por uma Educação do Campo, fruto da primeira "Conferência Nacional por Uma Educação Básica do Campo", ocorrida na cidade de Luziânia, Goiás, no ano de 1998. Esta conferência foi organizada por diversas entidades, tais como o Movimento dos Trabalhadores Rurais Sem Terra MST, por meio do Iterra; a Organização das Nações Unidas para a Educação, a Ciência e a Cultura - Unesco; o Fundo das Nações Unidas para a Infância - Unicef; a Confederação Nacional dos Bispos do Brasil - CNBB e a Universidade de Brasília $-\mathrm{UnB}$.

Essas articulações a partir de então foram impulsionando a existência de espaços de discussões, grupos de trabalho e políticas públicas, os quais deram base para o surgimento de diretrizes voltadas à Educação do Campo.

Nesse sentido, citam-se como exemplos de legislações: as Diretrizes Operacionais para Educação do Campo criadas em 2002, a Resolução CNE/CEB n. 2 de 2008 que estabelece diretrizes complementares, normas e princípios para o desenvolvimento de políticas públicas de atendimento da Educação Básica do Campo, complementando as Diretrizes Operacionais instituídas anteriormente, o Decreto Presidencial n. 7352 de 04 de novembro de 2010 que dispõe sobre a política de Educação do Campo e o PRONERA, definindo as características das escolas do campo, bem como o que é considerado como população do campo.

Ressalta-se que discussões sobre a Educação do Campo, a partir da primeira conferência mencionada anteriormente, avançaram tendo como pano de fundo a compreensão de que a Educação do Campo é um processo que gravita em torno dos direitos sociais, políticos e econômicos dos cidadãos, respeitando a diversidade sociocultural e econômica das comunidades, sendo assim, não pode acontecer pela simples transposição de modelos pré-definidos.

Igualmente, a que se considerar também a ligação com o trabalho no campo e como esta relação implica na permanência desses sujeitos em seu território que ultimamente tem-se tornado em um campo de disputa contraditório ao 
agronegócio e aos modelos de agricultura capitalista que vê o campo apenas pela lógica da reprodução do capital e não a do trabalho. Para Caldart (2009, p. 47) "a educação do campo acontece em um momento de potencial acirramento da luta de classes no campo motivada por uma ofensiva gigantesca do capital internacional sobre a agricultura", que em uma lógica perversa;

[..] expulsa trabalhadores do campo ao mesmo tempo em que promete incluí-los na modernidade tecnológica do agronegócio; subordina a todos de alguma forma, ao modelo tecnológico que vem sendo chamado de 'agricultura industrial' e mantém seus territórios de trabalho escravo [..]. A lógica de expansão do capitalismo no campo, ou lógica de pensar o campo como lugar de negócio, não inclui, não precisa das escolas do campo [..] (Caldart, 2009, p. 48).

Sob essa ótica, a resistência das escolas do campo, se mostra como o direito de seus trabalhadores em ter uma escola vinculada ao seu mundo real, despertando o entendimento de que sim, tem direito à educação em qualquer um de seus níveis e em seu lugar, podem continuar estudando no campo, sendo respeitados pelo que são e não ridicularizados e expulsos de seus territórios em busca de escolas para seus filhos. Estes processos de pensar o campo como "lugar" muito se deve a luta que os movimentos sociais balizaram no sentido da democratização da educação, movimentos estes dispostos a reagir e a ampliar o olhar destes sujeitos sobre seus direitos.

O espaço agrário brasileiro passa por diversas transformações, com significativos efeitos sobre seus conteúdos e funções, nas últimas décadas, especialmente após a metade do século XX, observa-se no nesse espaço um forte apelo para modelos agrícolas ligados ao agronegócio termo que passa a ser utilizado a partir de 1980 no Brasil, associado ao termo “Complexo Agroindustrial” (Matos \& Pêssoa 2011, p. 293),

O agronegócio se apresenta como uma versão contemporânea do capitalismo no campo, correspondendo a um modelo no qual a produção é organizada a partir de aparatos técnicos científicos, grandes extensões de terras, pouca mão-obra, predomínio da monocultura, dependência do mercado no quanto e como produzir, enfim, a empresas rurais. Para o Estado esse é o modelo que fez prosperar e desenvolver o campo brasileiro, porque contribuiu com o PIB (Produto Interno Bruto), responsável pelo crescimento da economia, empregos e produção de alimentos.

Fortemente seduzidos pelo capital e pela influência da mídia a modernização da agricultura, que para Graziano Silva (1996) é o termo utilizado para designar transformações na base técnica da produção agropecuária com modificação intensa das relações trabalho $\mathrm{x}$ capital e da própria produção do campo, grande parte do incentivo dado a agricultura está fortemente vinculado a monocultura e a produção em larga escala, ou seja, aos modelos 'agros' visando, sobretudo a exportação de grãos, sobre a prerrogativa de que somos "o celeiro do mundo".

Nesse ínterim, muitos se deixam seduzir pelo capital, em uma luta desigual, vendem suas terras buscando condições melhores de vida nas cidades e abandonam o campo. Tem ainda, aqueles, que mergulham em dívidas para tentar se adequar a um sistema que privilegia uma agricultura vinculada ao capital mascarada de uma agricultura voltada a soberania alimentar, desprezando as formas de produção e a ecologia de saberes que os povos campesinos trazem em seu bojo.

Fazendo um pequeno resgate sobre os processos de modernização do campo, voltamos ao ano de 1960, quando a adoção de tecnologias inovadoras no processo produtivo deu origem à constituição de "complexos agroindustriais" gerando uma nova configuração socioeconômica e espacial do espaço agrário brasileiro (Matos \& Pêssoa, 2011). Neste viés "a dependência de elementos externos à propriedade, a integração com a indústria, a circulação de produção em outros países, a mobilidade geográfica do capital produtivo e financeira são ditos como moderno" (Matos \& Pêssoa, 2011, p.292).

Porém, não se pode ser ingênuo em acreditar que todos os trabalhadores do campo que se deixam envolver pelo capital o fazem por querer este modelo para suas vidas/famílias, claro que também a que se considerarem aqueles que sim, sabem, querem e lutam por esse modelo. Muitos trabalhadores são obrigados a ceder às investidas do capital e aos modelos ou 
"pacotes" formatados para sua produção, uma vez que, os investimentos por parte de políticas públicas são na maioria das vezes destinadas àqueles que se submetem ao que determina o que plantar, quando plantar a quem vender e como vender/escoar sua produção.

Nesse sentido, o agro é "pop", pois, tenta se desvincular dos sistemas de plantation (Sistema agrícola baseado na monocultura de exportação mediante a utilização de latifúndios) com uma nova roupagem e sob a égide de "ouro verde" estão sempre a reivindicar do governo investimentos em infra-estrutura ampliação do comercio exterior, facilidades aduaneiras, pesquisas científicas e tecnológicas muitas vezes desenvolvidas em Universidades federais, com a ampliação de cursos superiores voltadas ao agronegócio (Fabrini, 2010).

Sendo assim, o 'pop' se alinha as empresas rurais, altamente tecnificadas, onde os modelos de produção agroecológicos não tem vez nem lugar, sendo o discurso do desenvolvimento que trás em seu bojo, a alteração dos biomas, territórios, e do próprio DNA da planta que prevalece nos modelos ditados pela produtividade, pois, contribui de forma significativa para o superávit da balança comercial brasileira, desta forma, "os fins justificariam os meios".

Neste meio, porém, encontram-se aquele/as agricultores/as, camponeses/as que lutam e resistem aos modelos determinados pelo capital, e que são massacrados pela falta de incentivo para produção de outras culturas que não aquelas voltadas para exportação que reverberam em commodities. Nos modelos de agricultura sustentável encontramos os sistemas agroecológicos os quais segundo Caporal e Costabeber (2007, p.71) a agroecologia é concebida como uma "ciência que estabelece as bases para a construção de estilos de agricultura sustentável e de estratégias de desenvolvimento rural sustentável”.

Não se pode cobrar dos agricultores familiares ou camponeses que produzam determinado cultivo se não tem demanda de mercado, essa demanda só é possibilitada através de políticas públicas e investimentos públicos voltadas para isso. Diferentemente da manipulação de produção existente através da monopolização do território, onde empresas se instalam em áreas estratégicas estabelecendo contratos com os camponeses e capitalistas que passam a produzir o que a empresa requer seguindo critérios de qualidade impostos pelas mesmas (Oliveira, 2006).

Nos modelos de agricultura sustentável os agricultores tentam resgatar como podem as sementes crioulas (que são aquelas sem modificações genéticas por meio de técnicas) muitas vezes auxiliados por instituições públicas de ensino e assim se mantém na contramão dos ditames mercadológicos, que só visam lucro, e propõe sistemas que auxiliam na soberania alimentar, tais como sistemas agroecológicos de produção, que respeitem a vida como um todo, enquanto a agricultura familiar se baseia na terra, trabalho e família os sistemas de agronegócio se baseiam no lucro e na renda (Matos \& Pêssoa, 2011).

A influência da mídia em propagandas que enobrecem o agronegócio colocando-o como salvador da pátria mascarando os verdadeiros números da agricultura brasileira, pois, tentam demostrar que o agronegócio é o grande gerador de empregos, o que de longe não é verídico, muito pelo contrário, fazem apologias à semifeudalidade, à semicolonialidade e até à escravidão nas imagens veiculadas pela mídia quando consideram tudo como "Agro".

Sendo assim, os modelos de agricultura sustentáveis que podem ser vivenciado e incentivado no campo vão ao encontro da conscientização, da compreensão do diálogo entre a terra e o trabalho, entre a saúde e o trabalho, entre o bem estar e o trabalho, entre a família e o trabalho, esta em um plano bem mais complexo do que apenas possuir um diploma, que lhe dá direito de um salário. Parte para uma compreensão do papel que se está desempenhando e na teia de tensões envolvidas na construção do conhecimento, uma vez que, o conhecimento esta atrelado a própria sobrevivência da espécie humana.

Nesse sentido, a Educação do Campo, toma o caminho contrário ao "Pop" do agro, pois, acredita na reapropriação do conhecimento coletivo superando a contradição existente entre trabalho manual e trabalho intelectual que se afirma e reafirma nos modelos de produção capitalista. A que se considerar também, que a educação do campo e para o campo está ligada fortemente aos educadores e educadoras que atuam nesse espaço, se as interrogações feitas no início deste item se vinculam as 
suas agendas então, estes educadores concebem a educação do campo a partir de sua gênese e conseguem entender o acirramento de contradições sociais que enfrentam e enfrentarão, pois, o campo está dentro da dinâmica do capitalismo e conceber a educação na prática é muito diferente que entendê-la na teoria.

\section{Metodologia}

Esta pesquisa envolveu 90 (noventa) discentes da disciplina intitulada "Seminário Integrador V", do curso de Licenciatura em Educação do Campo/UFSM/UAB. Estes alunos pesquisaram durante o segundo semestre do ano de 2019 diversas práticas de agricultura sustentável e saberes produzidos no campo. Estes dados foram registrados em diários de campo e posteriormente transcritos para relatórios apresentados ao final da disciplina. Retornando o total de 33 (trinta e três) relatórios destas práticas pesquisadas que foram analisados neste artigo. Os locais pesquisados foram na abrangência do espaço rural dos polos de apoio presencial do curso são eles: Polo de Agudo, São Sepé; Seberi, Itaqui e Cerro Largo, todos no estado do Rio Grande do Sul.

A metodologia seguida para a escrita do presente artigo se deu a partir de uma análise qualitativa dos relatórios apresentados, segundo Creswell (2007) na pesquisa qualitativa os pesquisadores fazem coleta de dados em um contexto natural, sensível às pessoas e aos lugares de estudo. Através do posicionamento dos pesquisadores diante do fato pesquisado, precedida da pesquisa bibliográfica que nos deu arcabouço teórico sobre as temáticas que foram elucidadas nos relatórios. Foi levado em consideração as percepções que os alunos tiveram sobre a necessidade e a importância dos conhecimentos produzidos fora da academia.

Para organização espacial do artigo, primeiramente se fez uma breve fundamentação teórica sobre a educação do campo e agroecologia o eixo norteador do curso de Licenciatura em Educação do Campo, na sessão 3 apresentamos os relatos/depoimentos retirados dos relatórios apresentados para finalmente teceremos as considerações finais.

\section{Resultados e Discussão}

Para organizar a análise dos dados obtidos utilizaremos a letra R (Relatório) seguida de número de 01, 02, 03... que representa o grupo que investigou e assim sucessivamente, trouxemos as percepções que aglutinam outras, sendo contemplado todos os relatórios apresentados.

O saber tradicional que mais apareceu nos relatos foi aquele que envolve uma prática de agricultura sustentável, muitos deles versando sobre sistemas agroecológicos, transição de monoculturas para policultivos, agricultura sustentável, alternativas ao uso de agrotóxicos, etc. Esses dados nos revelam que a agroecologia trouxe uma grande contribuição para a agricultura realizada em pequena escala proporcionando, dessa maneira, bases científicas para apoiar processos de transição a estilos de agriculturas de base ecológica ou sustentável (Caporal \& Costabeber, 2004).

Para o grupo de licenciandos que pesquisaram uma família que possui sua base econômica ancorada no cultivo de hortaliças, a pesquisa permitiu à eles:

“Esta pesquisa nos permitiu compreender o significado dos saberes tradicionais e seus aspectos. Apesar do trabalho normalmente ser considerado árduo, pesado, envolvendo esforço físico e exposição aos fenômenos naturais, mostrou que eles têm uma visão positiva do seu trabalho, principalmente com relação à liberdade, autonomia e bem estar junto à natureza." R01 
Compreender e respeitar as diversas formas de organização familiar, o modo como vivem, a cultura, seus sonhos e desejos são primordiais para o futuro educador do campo, pois, no decorrer de suas práticas pedagógicas deverão levar em consideração os sonhos e os saberes que seus alunos trazem para sala de aula, desmistificando que o campo é lugar de atraso e de exploração tanto das pessoas que ali vivem como dos recursos naturais a sua volta.

Para o licenciando que pesquisou um sistema de transição agroecológica em seu agrossistema a posição do mesmo diante da proposta da pesquisa foi que,

"Esta atividade proporcionou momentos importantes para mim como graduando da Licenciatura em Educação do Campo e também como educador em uma escola do campo, ao ampliar saberes, tanto técnicos quanto populares, a serem trabalhados academicamente e no ambiente escolar." R02

A troca de saberes fica evidenciada na fala do licenciando que aprendeu no momento da pesquisa, ilustrando desta forma a relação simbiótica que o educador do campo deve ter com seus educandos, pois,

Educar é promover a capacidade de ler a realidade e de agir para transformá-la. Para isso, a educação não pode se dar alheia ao contexto do educando, nem o conhecimento pode ser construído ignorando o saber dos alunos. Daí a importância da leitura do mundo. (Freire, 1997)

O grupo que pesquisou sobre Agricultura Orgânica seu relato nos mostra a importância da luta pela certificação dos produtos orgânicos, e tornar isso um processo conhecido pelos agricultores ainda se apresenta como desafio na localidade pesquisada.

"Para legitimação dos saberes da população campesina deveria haver uma valorização desses saberes, assim como um maior consumo de alimentos produzidos a partir desses saberes, para que a população perceba a qualidade desses alimentos e haja uma conscientização para o consumo de alimentos mais saudáveis e com mais sabor." (R03)

As licenciandas que pesquisaram o resgate de saberes como alternativas para o uso de agrotóxicos destacaram que:

"Ter a oportunidade de conhecer de perto uma família que preserva os saberes tradicionais de gerações é uma experiência incrível, e que agrega uma bagagem de conhecimentos na nossa formação, principalmente no conhecimento das plantas, os cuidados e na criação de pesticidas naturais para o controle de pragas, poluindo e prejudicando o nosso planeta minimamente. Pesquisar, estudar e refletir sobre esse tema foi de extrema valia, pois é necessário procurar formas mais naturais para realizar os plantios e os seus cuidados, precisamos urgentemente tentar minimizar os efeitos dos agrotóxicos no nosso planeta e precisamos aprender a cuidar da nossa terra, da nossa água e das nossas florestas, pois no momento que esses recursos naturais se esgotarem, a vida na terra não será mais possivel." (R04)

Nesse relato verificamos que o aprendizado foi além da pesquisa propriamente dita foi um conhecimento para a vida dos pesquisadores, que mencionaram a importância desses conhecimentos para a vida em qualquer lugar.

A possibilidade de conhecer diversos saberes locais, também foi elucidado durante a pesquisa, muito dos licenciandos não tem a vivencia do/no campo, reconhecendo que a pesquisa realizada foi importante para sua formação, 
"Esse trabalho foi de grande valia para nós acadêmicos de educação do Campo, pois ele nos abriu um leque sobre os saberes locais, coisas que aprendemos apenas na teoria, através de conhecimento científico. Esses saberes somente agregam aos conhecimentos, porque ninguém melhor que um agricultor, pecuarista... Enfim, sabe mais da prática destes manejos." (R05)

Houve também aqueles que além de pesquisar gostariam de auxiliar a família pesquisada como podemos observar no relato seguinte,

"A nossa sugestão é que esta atividade siga sendo utilizada nesta e em outras disciplinas, por ser incluída uma atividade prática de auxilio dentro da realidade familiar." (R06)

Também reconheceram que enquanto pesquisam aprendem com as vivências pesquisadas, mensurando que esses momentos da formação acadêmica são essenciais para a valorização, por parte do acadêmico, dos saberes tradicionais produzidos no campo, pois, "educar é ajudar a construir e a fortalecer identidades; desenhar rostos, formar sujeitos. Isso tem a ver com valores, modo de vida, memória, cultura" (Caldart, 2004a, p.42),

"A Disciplina Seminário Integrador V, além de proporcionar o contato direto com a agricultura familiar, possibilitou o conhecimento com a produção de agricultura familiar, onde se pode aprimorar a aprendizagem e o contato frente a prática oportunizada. Sendo de grande relevância e importância para que ocorra a valorização e o pertencimento dos saberes tradicionais do campo, como estudante e acadêmica do Curso de Licenciatura Educação do Campo." (R07)

Também foi possível observar nos relatos a valorização da mulher como gestora de uma propriedade do campo, indo na contramão daquilo que é mais vivenciado, que são os homens gestando e cuidando do campo enquanto a mulher assume o papel de submissão comum nas relações patriarcais do campo.

"A pesquisa realizada foi de suma importância pois permitiu a aproximação com uma unidade de produção para o acompanhamento de uma atividade de produção orgânica desenvolvida por uma gestora de uma propriedade coordenada por um homem que no restante da propriedade realiza atividade agrícola convencionais. ” (R08)

\section{Conclusão}

Relacionar a teoria com a prática foi o intuito da pesquisa realizada pelos licenciandos do $6^{\circ}$ semestre, aliar uma a outra faz parte do processo formativo do professor, a investigação também proporcionou entender o porquê de determinados saberes passados de geração em geração se tornarem um conhecimento científico.

Estar inserido na realidade que seus futuros alunos vivenciam os instiga a buscar praticas pedagógicas que vão ao encontro desta realidade. Com base nos relatos retornados das pesquisas realizadas pudemos perceber que os conhecimentos passados de geração em geração na sua maioria, estão associados com os modos de produção e a relação com a terra, fortemente influenciado pelos movimentos sociais do campo. Ser educador do campo então exige uma compreensão ampliada de seu papel, no qual a educação também passa ser uma prática social capaz de promover a articulação entre a escola e a comunidade. 
Sendo assim é mister que essas práticas já sejam desenvolvidas durante a formação acadêmica inicial, para que futuramente possam dar respostas a luta de tantas pessoas e coletivos que buscaram um educação do/no campo de qualidade valorizando as diversas formas de produção de conhecimento e saberes. Para trabalhos futuros acredita-se que a valorização dos saberes tradicionais nas escolas do/no campo devem ser pesquisadas, uma vez que, isso demonstrará como os profissionais que atuam nestes espaços vêem as questões inerentes a Educação do Campo.

\section{Referências}

Brasil. (2002). Resolução CNE/CEB $n^{o} 1$, de 3 de abril de 2002. Institui diretrizes operacionais para a educação básica das escolas do campo. Brasília. http://portal.mec.gov.br/cne/arquivos/pdf/CEB012002.pdf.

Brasil. (2008). Resolução $n^{\circ} 2$, de 28 de Abril de 2008. Diretrizes complementares, normas e princípios para o desenvolvimento de políticas públicas de atendimento da Educação Básica do Campo. http://portal.mec.gov.br/conaes-comissao-nacional-de-avaliacao-da-educacao-superior/323-secretarias112877938/orgaos-vinculados-82187207/12759-resolucoes-ceb-2008

Caldart, R. S. (2004a) Elementos para Construção do Projeto Político e Pedagógico da Educação do Campo. In: Molina, M. C. \& Jesus, S. M. S. A. de (Orgs.). Contribuições para a Construção de um Projeto de Educação do Campo. Brasília: Articulação Nacional Por uma Educação do Campo (Coleção Por uma Educação do Campo, caderno n. 5).

Caldart, R. S.(2009). Educação do campo: notas para uma análise de percurso. Trabalho, Educação, Saúde. 7(1), 35-64.

Caporal, F. R., \& Costabeber, J. A. (2002). Agroecologia: enfoque científico e estratégico. Agroecologia e Desenvolvimento Rural Sustentável, 3(2), 13-16.

Caporal, F. R., \& Costabeber, J. A. (2007). Agroecologia: alguns conceitos e princípios. (2a ed.), MDA: SAF: DATER-IICA.

Creswell, J. W. (2007). Projeto de Pesquisa: Métodos Qualitativo, Quantitativo e Misto. (2a ed.), Artmed, 248 p.

Graziano da S. J. (1996). Do complexo rural aos complexos industriais. In: Graziano, da S. J. A nova dinâmica da agricultura brasileira. UNICAMP/IE, p. 140 .

Matos, P. F., \& Pêssoa, V. L. S. (2011). A modernização da Agricultura no Brasil e os novos usos do território. Geo UERJ, p. 290-322. http://www.epublicacoes.uerj.br/index.php/geouerj/article/view/2456/1730.

MEC. Universidade Federal De Santa Maria. (2017). Projeto Pedagógico do Curso de Licenciatura em Educação do Campo. Pró-Reitoria de Graduação. UFSM, 270p.

Molina, M. C., \& Sá, L. M. (2012). Escola do Campo. In: Dicionário da Educação do Campo. Caldart, R. S., Pereira, I. B., Alentejano, Paulo \& Frigotto, G. (Orgs). Expressão Popular, 326-333.

Molina, M. C. \&Freitas, H. C. de A. (2011). Avanços e desafios na construção da Educação do Campo. Revista Em Aberto, 24(85), 17-31.

Fabrini, J. E. (2010). O campesinato frente à expansão do agronegócio e do agrocombustível. In: Saquet, M. A \& Santos, R. A. (Org.) Geografia agrária, território e desenvolvimento. Expressão Popular, p. 55-88.

Freire, P.(1997). Pedagogia da autonomia: saberes necessários à prática pedagógica. Paz e Terra.

Oliveira, A. U. (2006). O uso da terra, movimentos sociais e transformações no campo. In: Feitosa, A. M. A, Zuba, J. A. G \& Cleps J, J. (Org.). Debaixo da lona: tendências e desafios regionais da luta pela posse da terra e reforma agrária no Brasil. UCG, p. 29-78. 